\title{
Integration of Surgery and Radioembolization in Treatment of Hepatic Tumors
}

\section{Kevin Lowe and D. Rohan Jeyarajah}

Department of HPB Surgery and Surgical Oncology, Methodist Dallas Medical Center, Dallas, Texas

\section{Introduction}

The treatment of liver malignancies has evolved over recent decades. Historically, patients with liver tumors were considered incurable. With the advent of safer surgery and adjuncts such as radiospheres, patients can now enjoy long term survival and even cure in the face of liver tumors. Liver malignancies can either originate from the liver itself, such as hepatocellular carcinoma (HCC), or can metastasize to the liver from other sites; colorectal cancer liver metastasis (CRLM) being the most common example. There are many options for patients with liver tumors. Surgical resection remains the gold standard but ultimately can only be offered to $20 \%$ of patients with CRLM [1], most often because a functional liver remnant adequate to sustain life would not remain. This series of articles will cover the many options that are available to patients with liver tumors. Our aim here is to review the current literature concerning the multimodiality treatment of primary and metastatic liver tumors and to provide a surgical perspective regarding the rational use of non-resective therapy. Herein we will focus on the most common tumors of the liver: hepatocellular carcinoma (HCC), colorectal liver metastasis (CRLMs) and liver metastases from neuroendocrine tumors (NLMs). Other articles in this series will cover additional non - surgical treatment modalities which are available for patients with liver tumors. It is important to understand that only surgical resection offers a chance for a cure of primary liver tumors and liver only metastases. For this reason and because recent advances in multimodality treatment have increased the number of borderline resectable patients who ultimately undergo R0 resection, we advocate that surgical evaluation be included in the multidisciplinary work up of patients with liver tumors. For reasons discussed below, we believe that surgical evaluation is important even for those who may seem to be poor candidates for surgery due to multiple or very large tumors.

\section{Hepatocellular carcinoma}

Hepatocellular carcinoma (HCC) is the fourth leading cause of cancer-related deaths in the world, with most HCC occurring in the setting of cirrhosis and infection the hepatitis $\mathrm{B}$ or $\mathrm{C}$ viruses in the West. Largely due to a maturing population of Americans infected with hepatitis $\mathrm{C}$, the age adjusted American incidence of HCC has increased significantly in the last twenty years. In Asia, and Africa, infection by the hepatitis $B$ virus is the leading risk factor. An increased risk for the development of HCC are those with hepatitis B carrier state, chronic hepatitis $\mathrm{C}$ infection, hereditary hemochromatosis, cirrhosis of any etiology and some environmental exposures[2-5].

\section{Diagnosis of HCC}

The diagnosis of HCC is made on the basis of clinical and social history, radiologic appearance, serum alfa-fetal protein (AFP) level and biopsy. Infection with hepatis viruses carries significant risk of development of HCC in the setting of cirrhosis. In a recent study, North Americans with HCC were infected with hepatitis B virus (HBV) or hepatitis $\mathrm{C}$ cirus (HCV) $16 \%$ and $36 \%$ of the time, respectively [6]. In the Far East, the vast majority of patients with HCC are also infected with one of the hepatitis viruses [6]. While the majority of patients diagnosed with HCC and HCV infection will have cirrhosis[7], it is significantly less common to find cirrhosis in those who develop HCC in the context of hepatitis B infection [8]. Importantly, this is the more common background in which HCC develops in the Far East. While the majority of HCC develop in cirrhotics in the West this is not the case in the far east where the majority of HCC develops in patients with hepatitis B infection but no cirrhosis $[3,6]$. This may mean that patients with HCC in the Far East are more often candidate for surgical resection due to the absence of cirrhosis and decreased risk of post operative liver failure, an important point when comparing rusults of studies conducted in these populations.

The high incidence of HCC in cirrhotic has led to recommendations for surveillance of those with known cirrhosis, including ultrasound +/serum AFP measurement every 3 to 12 months [9-12]. Management of masses found in cirrhotics incidentally or via surveillance can be stratified according to size and appearance in imaging. A solid sub cm lesion which does not enhance on contrast imaging is unlikely to be HCC, and can be followed with repeated imaging every 3 to 6 months to verify absence of growth $[13,14]$. On the other hand, a 1-2 cm lesion which arises in a cirrhotic liver is more likely to be HCC. These smaller lesions are less likely to have the typical features of larger HCC lesion on imaging. For this reason percutaneous biopsy may remain a diagnostic tool in this group of patients $[9,15]$. Lesions greater than $2 \mathrm{~cm}$, which have a typical appearance on contrast imaging, found in a cirrhotic liver, and in a patient with elevated serum AFP are very likely to be HCC and can be treated as such without biopsy[16] (Figure 1). Biopsy has been associated with needle track seeding in $2-3 \%$ of punctures [15,17], and the risk of bleeding in $0.5 \%[18,19]$. Current guidelines suggest that typical appearance on two contrasted imaging modalities and a solid lesion greater than $2 \mathrm{~cm}$ in diameter has a positive predictive value of $95 \%$ regardless of AFP level, while any enhancing mass on imaging and an AFP of 200 is diagnostic $[9,16,20]$. Others believe that only an AFP value of 500has sufficient sensitivity[21]. It is important to note that up to $40 \%$ of HCCs will not produce AFP, and therefore a negative result does not exclude the diagnosis[10].

\section{Staging of HCC}

Staging of HCC can be done according to the tumor-nodemetastasis (TNM) system [22], or the united organ sharing system (UNOS). Both of these systems, however, do not include the extent of

*Corresponding author: D. Rohan Jeyarajah, MD FACS, Director Surgical Oncology/ HPB fellowship, Methodist Dallas Medical Center, 221 West Colorado Blvd, Suite 100, Dallas, TX 75208, E-mail: rjeyar@sadtx.com

Received April 26, 2011; Accepted May 26, 2011; Published June 15, 2011

Citation: Lowe K, Jeyarajah DR (2011) Integration of Surgery and Radioembolization in Treatment of Hepatic Tumors. J Nucl Med Radiat Ther 2:105. doi:10.4172/2155-9619.1000105

Copyright: ( 2011 Lowe K, et al. This is an open-access article distributed under the terms of the Creative Commons Attribution License, which permits unrestricted use, distribution, and reproduction in any medium, provided the original author and source are credited. 
underlying liver disease which has important implications for survival and surgical management [23]. Surgical planning is often aided by scoring systems such as the Child-Pugh classification which scores liver failure according to the presence of encephalopathy and ascites and the values of INR, albumin and bilirubin [24], or by the model for end stage liver disease (MELD) which is calculated based on creatinine, INR, and total bilirubin [25]. However, neither of these systems addresses the degree of tumor burden or extent of required resection. Other systems have been developed to have prognostic value which includes both tumor burden and underlying liver function [26-28], however these systems may not have prognostic value in non-surgical patients, and do not stratify patients sufficiently to guide treatment $[29,30]$. The Barcelona Clinic Liver Cancer (BCLC) staging system has had more prognostic value and links tumor stage to treatment strategy [31-34].

\section{Indications for resection of HCC}

Surgical removal of HCC offers the only hope for cure, but resection should only be undertaken in patients where there is an expectation of margin-negative (R0) resection and who will have adequate liver fuction perioperatively [33]. Advances in operative technique and perioperative care have greatly decreased the historical $30 \%$ mortality associated of major hepatic resection to a mortality of less than $5 \%$ in large volume centers[35]. Patients undergoing resection will have a 5 year survival of 10 to $70 \%[1,30,32,35,36]$. Multiple or large size lesions are not contraindications to resection in and of themselves. However, resection is contraindicated with tumor invasion of the main portal trunk, common hepatic artery, or inferior vena cava. Traditional chemotherapy alone induces minimal response and no survival advantage, while modern targeted therapies have shown minimal survival benefit [29]. Transarterial chemoembolizaiton (TACE), radiation therapy, ablation, and radiospheres will be discussed in more detail elsewhere in this issue.

Surgical management and indications are different for those with normal liver parenchyma and for those with fibrosis or cirrhosis. Our mandate at surgery is to leave enough functional liver to sustain life, but this clearly depends on the health of the liver prior to surgery. Five to 40 $\%$ of HCCs are found in non-cirrhotics, depending on the population studied $[6,8]$. For these patients, resection is the treatment of choice regardless of lesion size or number so long as two adjacent segments with blood inflow and outflow and intact biliary drainage remain after surgery. In general, at least $20 \%$ of pre-resection functional liver volume is required to avoid post hepatectomy failure in those without fibrosis or cirrhosis. The term "functional liver remnant" (FLR) is used to refer to the segments of liver that will be left after a resection. A patient with minimal liver injury (for example stage 2 fibrosis) can generally tolerate an FLR of 40\% [37]. The remaining HCC develop in cirrhotic livers. For these cases surgical decision making is more nuanced. The expectation of tumor progression should be weighed against the dangers of ongoing liver failure in consideration of appropriate therapy. Portal hypertension makes surgical and post surgical care challenging and low liver function to liver volume ratio allows less aggressive resections due to an increased incidence of postoperative hepatic failure. Guidelines suggest resection in cirrhotics only for those with small lesions, normal bilirubin and with no or minimal portal hypertension $[9,32]$. In our experience, good outcomes can be expected in those with liver disease when resection removes no more than 2 segments, bilirubin is less than 3 and there is neither portal hypertension nor ascites.

Even with appropriate resection and clear margins, because the cirrhotic liver represents a 'field defect', there is high likelihood of new or recurrent disease after resection of portion of the liver containing a known HCC $[38,39]$. In addition, the function of the remaining liver is suspect in cirrhosis leading to greatly increased risk of liver failure after resection. Both the 'field defect' and liver failure are treated with orthotopic liver transplantation (OLT), which may be curative in those with HCC and cirrhosis. As discussed below, when appropriate and available, OLT is the preferred therapy for those with HCC and cirrhosis.

Tumor recurrence is common in patients with resected HCC, particularly when microvascular invasion or satellite nodules are found on pathologic analysis of the surgical specimen [38,40,41]. Multimodality treatment including repeat resection may lead to prolonged survival in patients with recurrent disease, but are not generally curative.

While resection offers the best chance for cure for HCC in selected patients, it comes with the highest risk and requires careful preoperative assessment of both liver function and the patient's functional status. For patients with resectable disease, normal or near normal liver function and sufficient physiologic reserve, resection can be curative. We utilize non-resective therapies to palliate or convert unresectable disease, or as a bridge to OLT when appropriate.

\section{Indications for orthotopic liver transplant (OLT) in HCC}

In cirrhotic patients with HCC, recurrence is high due to a 'field defect', and morbidity after resection is much higher in cirrrhotics than in non cirrhotics. OLT treats two life threatening issues:

\section{1) HCC recurrence within the liver}

2) Underlying risk of death from chronic liver disease (for example variceal bleeding, ascites, etc)

For these reasons, in selected patients with cirrhosis and HCC, survival is better for those for whom orthotopic liver transplantation is performed than for those treated with resection [42,43]. Generally referred to as the Milan criteria, patients with cirrhosis and HCC may be candidates for transplantation if they have a single lesion of less than $5 \mathrm{~cm}$ diameter or 2 or 3 lesions none greater than $3 \mathrm{~cm}$ in diameter and with no gross vascular invasion [44]. (Table 1) A recent retrospective

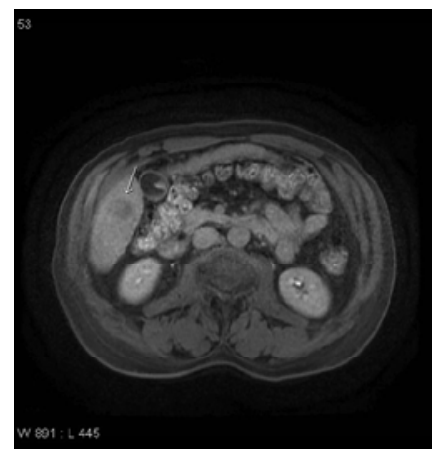

A

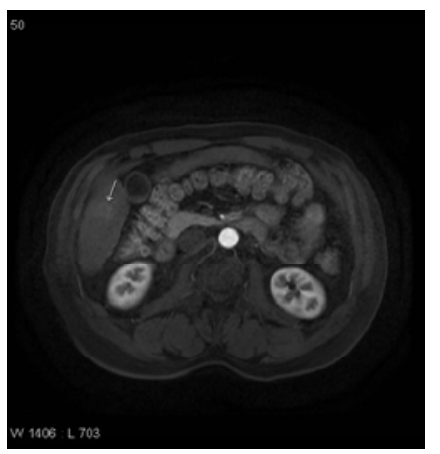

B
Figure 1: Lowe, Jeyarajah

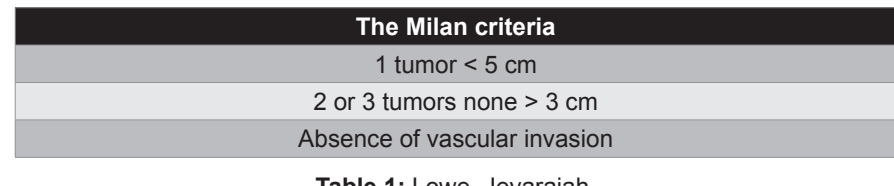

Table 1: Lowe, Jeyarajah. 


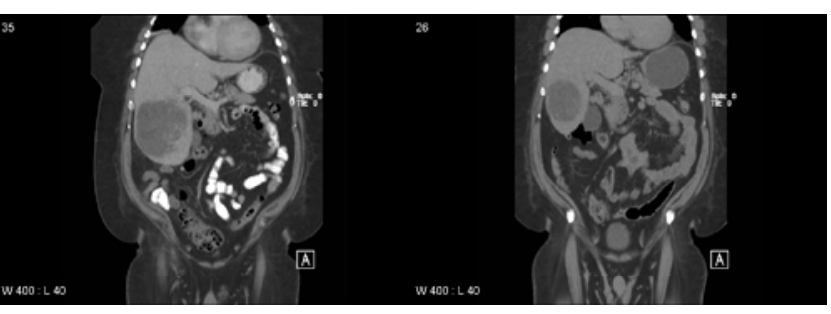

A

Figure 2: Lowe, Jeyarajah

analysis of patients treated within these criteria found a $66 \% 5$ year recurrence free survival in those who had OLT versus $26 \%$ after partial hepatectomy [45]. Interestingly, a recent report using criteria which included larger lesions has shown similar survival [46]. In 2002, to prioritize patients waiting for OLT, use of the model for end stage liver disease (MELD) score (derived from measurement of INR, total serum bilirubin and serum creatinine) was implemented to guide organ allocation. Since then, because the MELD score does not consider progression of malignant disease in those with adequate liver function, changes were made in the selection process to add MELD points for a diagnosis of HCC [47]. Though there have been a number of changes in the system since 2002, currrently a diagnosis of HCC earns a score of 22 points for those with stage II HCC. Acccording to current UNOS guidelines, those with stage I, III and IV disease do not receive extra MELD points for the diagnosis, though these exclusions are a matter of significant debate $[48,49]$.

Thus, resection and OLT are the two potentially curative options for patients with HCC, while other modalities are largely adjuvant or palliative [29]. When the risk of death from progression of liver disease is less than risk of undergoing surgery, hepatectomy is the treatment of choice in those with HCC. However, in cases where ongoing liver disease is a greater threat to life than that posed by surgery and where resection increases the likelihood of liver failure, OLT should be used to treat both the cancer and the liver disease.

\section{Non-curative treatments of HCC}

In patients with small tumors, radio frequency ablation (RFA) or microwave ablation (MA) may allow long term survival. However, local recurrence rates are high in those with tumors greater than $3 \mathrm{~cm}$, when the tumor is close to a major vessel, or when done laproscopically or percutaneously, limiting the use of RFA or MA as a curative therapy[50,51]. In patients whose liver disease is or will become life threatening, TACE, RFA or MA may serve as a bridge to transplantation [52-54]. RFA, MA or intra-arterial treatments may allow local control in a palliative setting and in some patients may down stage disease sufficiently to make unresectable disease resectable [55]. (Figure 2).

In summary, Western HCC develops most commonly in the context of cirrhosis. Minimal resections can be performed in this patient population, but careful thought should be given to OLT because OLT will treat the underlying liver disease-related mortality and the HCC-related mortality.

\section{Colorectal liver metastases}

Approximately $25 \%$ of patients diagnosed with colorectal cancers will present with liver - only metastases at the time of initial presentation and $50 \%$ of patients with colorectal cancer will develop liver metastasis during the course of their disease. Of those diagnosed with liver metastasis at presentation $20 \%$ will be candidates for surgery. Effective treatment of colorectal cancer with liver metastases may require any or all of the following, neoadjuvant and/or adjuvant systemic chemotherapy, transarterial chemo- embolization (TACE), resection of the primary and/or liver metastasis, re-resection of liver metastasis, portal vein embolization, surgical or percutaneous ablation, or radioactive partical infusion (y90). As many of these options are not mutually exclusive, we advocate a multidisciplinary approach to the treatment of CRLM.

\section{Rational for resection of colorectal liver metastasis}

In contrast to other types of cancers in which metastatic disease is not resected for cure, survival benefit and possible cure is achievable by resection of colorectal disease which has liver only metastases $[56,57]$. In fact, patients without resection of CRLM have a mean survival of 5 - 13 months, while 5 year survival after resection is as high as $71 \%$ in those with single liver lesions [58], and 5 year survival is achievable even in patients with 4 or more CRLMs [59]. These improvements in overall survival are also made possible by decreasing mortality associated with liver resection performed at high volume centers over the last two decades. Chemotherapy has increased survival in patients with metastatic colorectal cancer, but cure is not possible without surgical resection. All patients with CRLM should be evaluated by an experienced HPB surgeon to ensure that they are not, or can never be, a surgical candidate. There are many adjuncts available to make even initially unresectable lesions resectable, and therefore the decision to not offer patients surgery should only be made by a surgeon that is comfortable with major liver resections and who is familiar with other modalities such as portal vein embolization (PVE)- see below.

\section{Indications for resection of colorectal liver metastases}

As is the case in planning resection for HCC, the number and size of tumors do not play directly into the decision whether or not to perform hepatactomy for CRLMs. Rather, potentially resectable CRLMs are defined by the expectation of an R0 resection which will preserve two contiguous liver segments with adequate inflow, outflow and biliary drainage with an FLR of greater than $20 \%-30 \%$ of preoperative volume. In 2004 the EORTC 40983 trial included for resection those patients with 4 or fewer CRLMs [60]. Most liver surgeons have not followed these criteria in practice however, preferring to focus on disease clearance and adequate remnant liver volume irrespective of the number of metastasis [61]. Traditionally a margin of $1 \mathrm{~cm}$ has been the standard for optimum clearance of tumor. However, similar outcomes were seen in patients with microscopically negative margins less than $1 \mathrm{~cm}$ versus those with greater than $1 \mathrm{~cm}$ margins [62]. In addition to anatomical evaluation for resection, tumor biology should be assessed because the risks of resection may not be justified for a patient with a tumor which is very likely to progress. Primary disease stage, rate of rise of carcinoembyonic antigen (CEA), number and distribution of CRLM, differentiation of the tumor and response to chemotherapy may provide clues as to the likelihood of progression [63]. Fong et al developed a clinical risk score in which a node-positive primary, less than 12 month diseases free interval, 2 or more metastases, CEA greater than 200, and primary tumor larger than $5 \mathrm{~cm}$, are associated with decreased survival [64]. This and other scoring systems have been shown to accurately predict survival in patients with CRLMs $[65,66]$ The surgical management of CRLMs differs from that of primary liver tumors because the handling of the metastasis must be considered in the context of treatment of the primary tumor. Our practice is to obtain a CT of the chest abdomen and pelvis with IV contrast preoperatively to 


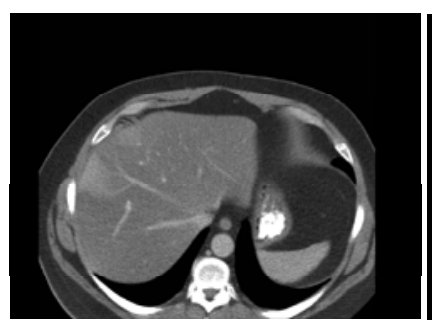

A

Figure 3: Lowe, Jeyarajah.

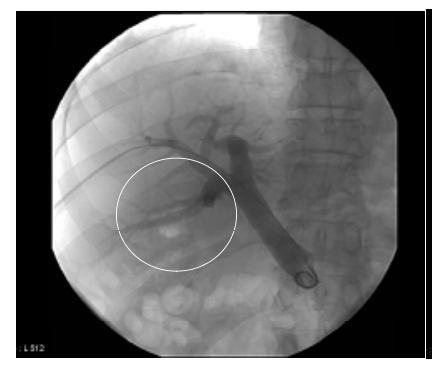

A

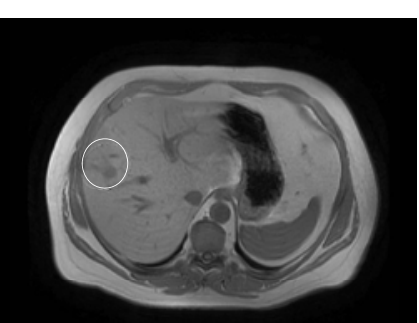

B

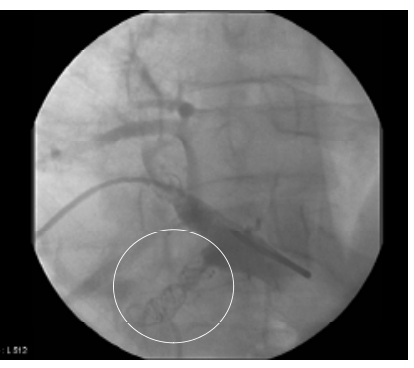

Figure 4: Lowe, Jeyarajah

determine disease stage. Preoperative percutaneous biopsy is generally not warranted in the context of known colorectal cancer and a typical appearance on imaging, and has been associated with decreased survival due to tumor dissemination [67]. We have found that for questionable cases, MRI using the hepatocyte labeling contrast gadoxetate disodium (EOVIST, Bayer HealthCare Pharmaceuticals Inc., Wayne, NJ) can be very helpful in delineating number and distribution of metastasis and in confirming the presence of non - hepatocyte containing solid tissue masses (Figure 3).

Currently, patients with an expected FLR of greater than $20 \%$ and who have favorable tumor biology should be considered for surgical resection of CRLM. This decision should be made in the context of a multidisciplinary conversation that includes the oncologist, interventional radiologist and the HPB surgeon.

\section{Evidence regarding chemotherapy prior to hepatectomy}

Chemotherapy prior to liver resection can be given in the setting of synchronously presenting primary and liver metastases, or after a disease free interval following resection of the primary lesion. In synchronous disease, preoperative chemotherapy may;

1) lead to smaller resections,

2) convert a non- resectable patient to resectable,

3) or identify patients with disease which will not respond to chemotherapy, who will be poor candidates for aggressive surgical therapy.

The reasons not to use chemotherapy preoperatively, but rather use it only post - operatively, are:

1) lack of interruption of chemotherapy by surgery and possible surgical complications,

2) hepatotoxicity of chemotherapeutic agents, and

3) the attendant increased risk of surgical complications after exposure to chemotherapy
Data concerning outcomes relative to use of preoperative chemotherapy have been contradictory. In the most severe cases of oxaliplatin induced vascular lesions, operative bleeding and transfusions were greater $[68,69]$. Oxaliplantin also induces steatosis which has been linked to increased morbidity and infectious complications $[70,71]$ Steatohepatis related to iranotecan treatment was linked to increased mortality due to liver failure, though these findings have not been replicated [69]. Based on the findings of Karoui et al in which morbidity was increased in patients who received more than 6 cycles of chemotherapy preoperatively, it is our practice to operate after 3-6 cycles of systemic chemotherapy [72]. The value of this approach has been recently confirmed by the EORTC intergroup RCT, in which six cycles of FOLFOX plus resection improved survival versus surgery alone [60]. Concerns that the VEGF receptor blocker bevicizumab may have an additive effect on liver damage have not borne out $[73,74]$.

\section{Management of synchronous CRLMs}

Management of synchronously presenting primary colorectal mass and liver metastasis presents the unique problem of multiple options for the chronologic staging of systemic chemotherapy, local radiologic techniques and liver and colon resections. In the presence of an obstructing or bleeding colon lesion, decision making is simplified by the urgent presentation. In cases that do not present with emergent complications, some authors suggest immediate liver resection to avoid the surgical morbidity associated with preoperative chemotherapy. Evidence and personal experience suggest that these morbidities can be avoided by performing resection after no more than 6 cycles with oxaliplatin based therapy [72]. The advantages of giving neoadjuvant chemotherapy were discussed above, but include potential shrinkage of tumor and avoidance of unnecessary resection in those with aggressive disease. Consensus is lacking regarding the timing of surgery to remove the primary tumor and the metastases. Currently, our preference is to perform 3-6 cycles of oxaliplatin based chemotherapy prior to liver resection. The liver is then considered the first order of concern and we resect the liver metastases first if possible. The role of combined colon and liver resections are a topic of debate $[75,76]$. It is our preference to perform synchronous colon and liver resections if the patient is fit and the liver resection has gone well with minimal blood loss. A staged approach allows frequent re-evaluation of disease biology and patients specific intervention with regard to timing and dose of chemotherapy. When the primary tumor is in the rectum, we advocate sequencing in radiation therapy after liver resection and completion of FOLFOX based chemotherapy. PVE may become important to maximize FLR when the liver is exposed to extensive chemotherapy prior to resectionsee below.

\section{Portal Vein Embolization}

As discussed above, resection may not be an option for patients with large or multiple lesions due to inadequate FLR. In an attempt to increase the number of patients who can benefit from resection, portal vein embolization has been used in some patients with predicted borderline FLR [77]. Occluding portal vein flow to the diseased hemiliver causes atrophy of the embolized segments and hypertrophy of the contralateral liver [78] (Figure 4). This occurs quickly. Within three weeks of PVE there will be demonstrable growth in the FLR. (Figure 5) Despite the fact that fibrotic and cirrhotic livers have impaired regeneration capacity, increase in functional liver remnant does occur in diseased livers after PVE. In fact, PVE may be more useful prior to resection of diseased livers than in those with normal liver parynchyma. Failure of the contralateral liver to hypertrophy is a 


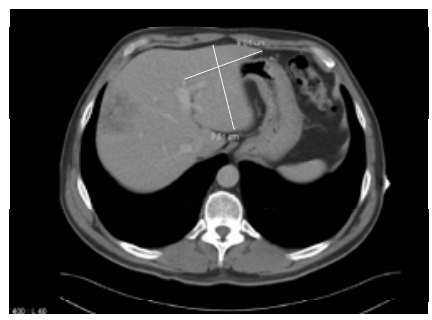

A

Figure 5: Lowe, Jeyarajah.

\section{Portal Vein embolization}

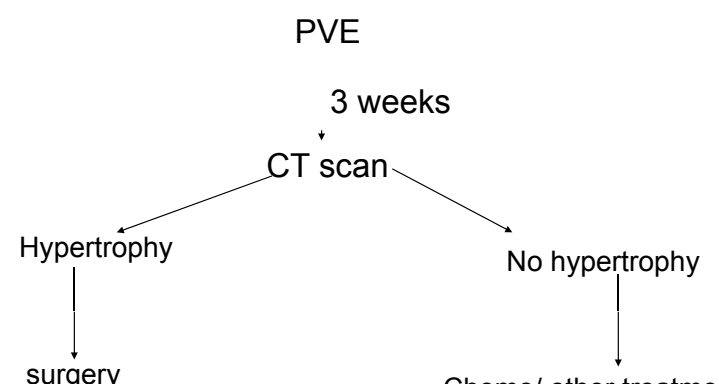

Figure 6: Lowe, Jeyarajah
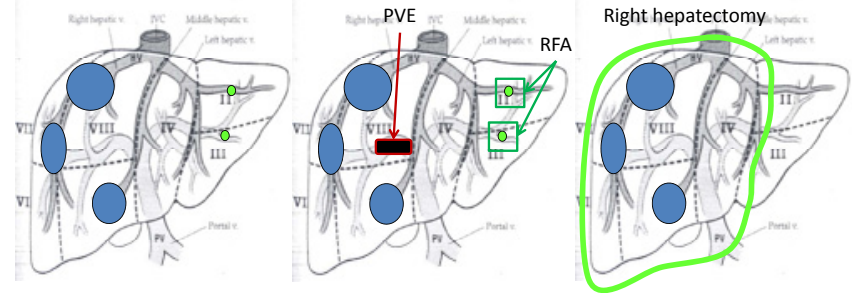

Figure 7: Lowe, Jeyarajah

negative predictive factor for liver failure after resection [79]. (Figure 6) Current practice suggests PVE in cirrhotic livers where the FLR will be less than $40 \%$ and PVE for an estimated FLR of less than $20-30 \%$ in those without parenchyma liver disease $[77,80]$. Due to chemotherapy related liver injury, PVE is suggested for those who have been treated with chemotherapy and have a predicted FLR less than $40 \%$ [77]. For CRLMs or neuroendocrine tumors, planned PVE with repeat resection or ablation may allow a disease free liver remnant in patients who would otherwise be unresectable (Figure 7).

In summary, resection is the only modality that can provide a cure for patients with CRLM. Chemotherapy can prolong life but cannot cure patients with CRLMs. Bilobar and extensive disease are not a contraindication for resection in patients who have favorable tumor biology otherwise. PVE and other adjuncts can result in allowing resection of marginally resectable lesions.

\section{Neuroendocrine liver metastasis}

Neuroendocrine liver metastases (NLM) develop in $46 \%$ to 93 $\%$ of patients with neuroendocrine malignancy, and the diagnosis of neuroendocrine disease is often made when hormone production by intrahepatic metastases overwhelms the metabolic clearance of homone by the liver itself. Metastatic disease is often multifocal, but morbidity and mortality more often results from excessive hormone production than by tumor invasion of normal tissues.

\section{Rational for resection of neuroendocrine liver metastasis}

NLM have a limited response to systemic chemotherapy with the presence of liver metastasis being the most significant predictor of outcome [81]. Other non - surgical approaches such as ${ }^{131}$ I-metaiobenzylguanidine (MIBG) therapy and and ${ }^{111}$ In-octreotide therapy have a limited duration of response. Resection represents the only hope for long term survival benefit and prolonged improvement in symptoms.

\section{Indications for resection of neuroendocrine liver metastases}

Because NLM are often multifocal, only $10 \%$ - $20 \%$ of patients with NLM are candidates for surgical removal of all metastases, however, prolonged symptom free survival can be expected if at least $90 \%$ of metastasis are resected or ablated $[82,83]$. Though metastatic recurrence occurs in up to $80 \%$, the overall indolent nature of the disease allows for long symptom free intervals and prolonged survival after surgical treatment. However, non-functional NETs are more often associated with high grade malignancy and worse survival when compared with functional NETs [84]. Large and small cell tumors also have particularly aggressive biology [85]. For all tumor types, current recommendations are for complete resection of disease provided an adequate FLR remains, and surgical de-bulking if at least $80-90 \%$ of tumor mass can be removed and symptoms are severe in spite of non - operative treatment, or if mass effect threatens survival $[30,82,83,86]$. Surgical debulking can be used in conjunction with RFA or MA to provide symptomatic relief when resection alone cannot remove sufficient tumor $[87,88]$.

\section{Surgical therapy for neuroendocrine liver metastases}

Similar to operation for CRLM, resection is warranted when disease can be removed leaving a tumor free FLR of at least $20 \%$ and with adequate blood inflow and outflow. Surgical debulking with or without ablation can effectively relieve symptoms and prolong survival when complete removal of all diseased liver is not possible, or when extra - hepatic metastases exist. However, experience suggests high recurrence when NLM larger than $3 \mathrm{~cm}$ are treated with RFA $[89,90]$. Adjuvant treatment with octreotide or interferon a decreases symptoms after resection or ablation [91]. NLM derive their blood supply almost exclusively from the arterial system allowing directed treatments via cannulation of the hepatic artery and its branches [92]. For non-resectable disease, hepatic arterial therapy may provide symptomatic relief and increase survival [92-95]. Experience with OLT for neuroendocrine liver metastases has been limited, but suggests worse outcomes than those for other indications [96].

In summary, NLMs occur in a majority of patients with neroendocrine tumors, but a small proportion of patients are suitable for liver resection. However, when possible, liver resection for NLMs can allow prolonged symptom free survival. Medical therapies provide only limited symptom free intervals and are not curative in intent. OLT does not likely improve outcomes for NLMs.

\section{Conclusion}

Treatment of primary and metastatic liver tumors requires navigation of complex decision trees which rely on multimodality treatment options. For HCC, the only potentially curative treatment 
Citation: Lowe K, Jeyarajah DR (2011) Integration of Surgery and Radioembolization in Treatment of Hepatic Tumors. J Nucl Med Radiat Ther 2:105. doi:10.4172/2155-9619.1000105

Page 6 of 8

options are resection and OLT. For single HCC tumors in patients with normal liver function, resection provides equivalent of better long term survival to OLT. However, when liver disease threatens survival, OLT is the treatment of choice. Current selection criteria weigh heavily in favor of those with stage 2 HCC, leaving many patients unlikely to undergo OLT.

Resection of CRLMs can also lead to long term survival. Even in those who do not achieve cure, our increasing competence with multimodality treatment of CRLMs has led to a paradigm shift such that CRLMs are increasingly a disease patients live with, rather than die from. Though many NLMs will recur, long term survival is the norm after resection because of a general indolent biology. OLT does not improve survival in metastatic disease.

OLT is the best option for HCC when criteria are met. However, when OLT is not an option, and complete removal of all known disease is possible via a liver resection which leaves adequate liver volume to support life, resection is the gold standard. Mutlimodality treatment via TACE, ablation, PVE, radioembolization and other local therapies can act as a bridge to transplantation in HCC and can sometimes convert non resectable patients with HCC or metastatic disease. We regard ongoing multimodality assessment, and early involvement of an experienced surgeon as standard of care for those with primary or metastatic liver tumors. Thus, resection and OLT are the two potentially curative options for patients with HCC, while other modalities are largely adjuvant or palliative [29]. When the risk of death from progression of liver disease is less than risk of undergoing surgery, hepatectomy is the treatment of choice in those with HCC. However, in cases where ongoing liver disease is a greater threat to life than that posed by surgery and where resection increases the likelihood of liver failure, OLT should be used to treat both the cancer and the liver disease.

\section{References}

1. Adam R, Avisar E, Ariche A, Giachetti S, Azoulay D, et al. (2001) Five-yea survival following hepatic resection after neoadjuvant therapy for nonresectable colorectal. Ann Surg Oncol 8: 347-53

2. Nordlinger B, Vaillant JC, Guiguet M, Balladur P, Paris F, et al. (1994) Survival benefit of repeat liver resections for recurrent colorectal metastases: 143 cases. Association Francaise de Chirurgie. J Clin Oncol 12: 1491-1496.

3. El-Serag HB (2002) Hepatocellular carcinoma: an epidemiologic view. J Clin Gastroenterol, 2002. 35: S72-78.

4. El-Serag HB, Marrero JA, Rudolph L, Reddy KR (2008) Diagnosis and treatment of hepatocellular carcinoma. Gastroenterology 134: 1752-1763.

5. El-Serag HB, Mason AC (1999) Rising incidence of hepatocellular carcinoma in the United States. N Engl J Med 340: 745-750.

6. Venook AP, Papandreou C, Furuse J, de Guevara LL (2010) The incidence and epidemiology of hepatocellular carcinoma: a global and regional perspective. Oncologist 15: 5-13.

7. But DY, Lai CL, Yuen MF (2008) Natural history of hepatitis-related hepatocellular carcinoma. World J Gastroenterol 14: 1652-1656.

8. El-Serag HB, Rudolph KL (2007) Hepatocellular carcinoma: epidemiology and molecular carcinogenesis. Gastroenterology132: 2557-2576.

9. Bruix J, Sherman M, Llovet JM, Beaugrand M, Lencioni R, et al. (2001) Clinical management of hepatocellular carcinoma. Conclusions of the Barcelona-2000 EASL conference. European Association for the Study of the Liver. J Hepato 35: $421-430$

10. Ferenci P, Fried M, Labrecque D, Bruix J, Sherman M, et al. (2010) World Gastroenterology Organisation Guideline. Hepatocellular carcinoma (HCC): a global perspective. J Gastrointestin Liver Dis 19: 311-317.

11. Bolondi L (2003) Screening for hepatocellular carcinoma in cirrhosis. J Hepatol 39: 1076-1084.
12. Zhang BH, Yang BH, Tang ZY (2004) Randomized controlled trial of screening for hepatocellular carcinoma. J Cancer Res Clin Oncol 130: 417-22.

13. Iwasaki M, Furuse J, Yoshino M, Ryu M, Moriyama N, et al. (1998) Sonographic appearances of small hepatic nodules without tumor stain on contrast-enhanced computed tomography and angiography. J Clin Ultrasound 26: 303-307.

14. Fracanzani AL, Burdick L, Borzio M, Roncalli M, Bonelli N, et al. (2001) Contrast-enhanced Doppler ultrasonography in the diagnosis of hepatocellular carcinoma and premalignant lesions in patients with cirrhosis. Hepatology 34 1109-1112.

15. Torzilli G, Minagawa M, Takayama T, Inoue K, Hui AM, et al. (1999) Accurate preoperative evaluation of liver mass lesions without fine-needle biopsy. Hepatology 30: 889-893.

16. Levy I, Greig PD, Gallinger S, Langer B, Sherman M (2001) Resection of hepatocellular carcinoma without preoperative tumor biopsy. Ann Surg 234 206-209.

17. Cabibbo G, Craxi A (2009) Needle track seeding following percutaneous procedures for hepatocellular carcinoma. World J Hepatol 1: 62-66.

18. Atwell TD, Smith RL, Hesley GK, Callstrom MR, Schleck CD, et al. (2010) Incidence of bleeding after 15,181 percutaneous biopsies and the role of aspirin. AJR Am J Roentgenol 194: 784-789.

19. Seeff LB, Everson GT, Morgan TR, Curto TM, Lee WM, et al. (2010) Complication rate of percutaneous liver biopsies among persons with advanced chronic liver disease in the HALT-C trial. Clin Gastroenterol Hepatol 8: 877-883.

20. Trevisani F, D'Intino PE, Morselli-Labate AM, Mazzella G, Accogli E, et al (2001) Serum alpha-fetoprotein for diagnosis of hepatocellular carcinoma in patients with chronic liver disease: influence of $\mathrm{HBsAg}$ and anti-HCV status. J Hepatol 34: 570-575.

21. Poon TC, Mok TS, Chan AT, Chan CM, Leong V, et al. (2002) Quantification and utility of monosialylated alpha-fetoprotein in the diagnosis of hepatocellular carcinoma with nondiagnostic serum total alpha-fetoprotein. Clin Chem 48 1021-1027.

22. Cancer AJC (2010) AJCC Cancer Staging Manual. Vol. Chapter ? Berlin Germany: Springer.

23. Mino M, Lauwers GY (2003) Pathologic spectrum and prognostic significance of underlying liver disease in hepatocellular carcinoma. Surg Oncol Clin N Am 12: $13-24$.

24. Pugh RN, Murray-Lyon IM, Dawson JL, Pietroni MC, Williams R (1973) Transection of the oesophagus for bleeding oesophageal varices. $\mathrm{Br} \mathrm{J}$ Surg 60: 646-649.

25. Malinchoc M, Kamath PS, Gordon FD, Peine CJ, Rank J, et al. (2000) A model to predict poor survival in patients undergoing transjugular intrahepatic portosystemic shunts. Hepatology 31: 864-871.

26. Vauthey JN, Lauwers GY, Esnaola NF, Do KA, Belghiti J, et al. (2002) Simplified staging for hepatocellular carcinoma. J Clin Oncol 20: 1527-1536.

27. Okuda K, Ohtsuki T, Obata H, Tomimatsu M, Okazaki N, et al. (1985) Natural history of hepatocellular carcinoma and prognosis in relation to treatment Study of 850 patients. Cancer 56: 918-928.

28. Stuart KE, Anand AJ, Jenkins RL (1996) Hepatocellular carcinoma in the United States. Prognostic features, treatment outcome, and survival. Cancer 77: 2217 2222.

29. Rahbari NN, Mehrabi A, Mollberg NM, Müller SA, Koch M, et al. (2011) Hepatocellular carcinoma: current management and perspectives for the future. Ann Surg 253: 453-469.

30. Blumgart L (2007) Surgery of the liver, Biliary Tract and Pancreas. 4th ed Vol 2 Sanders: Philadelphia PA.

31. Marrero JA, Fontana RJ, Barrat A, Askari F, Conjeevaram HS, et al. (2005) Prognosis of hepatocellular carcinoma: comparison of 7 staging systems in an American cohort. Hepatology 41: 707-716.

32. Llovet JM, Bru C, Bruix J (1999) Prognosis of hepatocellular carcinoma: the BCLC staging classification. Semin Liver Dis 19: 329-338.

33. Bruix J, Boix L, Sala M, Llovet JM (2004) Focus on hepatocellular carcinoma Cancer Cell 5: 215-219.

34. Bruix J, Llovet JM (2003) Hepatitis B virus and hepatocellular carcinoma. J Hepatol 39: 59-63. 
Citation: Lowe K, Jeyarajah DR (2011) Integration of Surgery and Radioembolization in Treatment of Hepatic Tumors. J Nucl Med Radiat Ther 2:105. doi:10.4172/2155-9619.1000105

35. Grazi GL, Ercolani G, Pierangeli F, Del Gaudio M, Cescon M, et al. (2001) Improved results of liver resection for hepatocellular carcinoma on cirrhosis give the procedure added value. Ann Surg 234: 71-78.

36. Fong Y, Sun RL, Jarnagin W, Blumgart LH (1999) An analysis of 412 cases of hepatocellular carcinoma at a Western center. Ann Surg 229: 790-799.

37. Vauthey JN, Dixon E, Abdalla EK, Helton WS, Pawlik TM, et al. (2010) Pretreatment assessment of hepatocellular carcinoma: expert consensus statement. HPB (Oxford) 12: 289-299.

38. Llovet JM, Fuster J, Bruix J (1999) Intention-to-treat analysis of surgical treatment for early hepatocellular carcinoma: resection versus transplantation. Hepatology 30: 1434-1440.

39. Ercolani G, Grazi GL, Ravaioli M, Del Gaudio M, Gardini A, et al. (2003) Liver resection for hepatocellular carcinoma on cirrhosis: univariate and multivariate analysis of risk factors for intrahepatic recurrence. Ann Surg 237: 536-543.

40. Okada S, Shimada K, Yamamoto J, Takayama T, Kosuge T, et al. (1994) Predictive factors for postoperative recurrence of hepatocellular carcinoma. Gastroenterology 106: 1618-1624

41. Adachi E, Maeda T, Matsumata T, Shirabe K, Kinukawa N, et al. (1995) Risk factors for intrahepatic recurrence in human small hepatocellular carcinoma. Gastroenterology 108: 768-775

42. Lee KK, Kim DG, Moon IS, Lee MD, Park JH et al. ( 2010) Liver transplantation versus liver resection for the treatment of hepatocellular carcinoma. J Surg Oncol 101: 47-53.

43. Bismuth H, Chiche L, Adam R, Castaing D, Diamond T, et al. (1993) Liver resection versus transplantation for hepatocellular carcinoma in cirrhotic patients. Ann Surg 218: 145-151.

44. Mazzaferro V, Regalia E, Doci R, Andreola S, Pulvirenti A, et al. (1996) Liver transplantation for the treatment of small hepatocellular carcinomas in patients with cirrhosis. N Engl J Med 334: 693-699.

45. Sotiropoulos GC, Drühe N, Sgourakis G, Molmenti EP, Beckebaum S, et al. (2009) Liver transplantation, liver resection, and transarterial chemoembolization for hepatocellular carcinoma in cirrhosis: which is the best oncological approach? Dig Dis Sci 54: 2264-2273.

46. Yao FY, Ferrell L, Bass NM, Watson JJ, Bacchetti P, et al. (2001) Liver transplantation for hepatocellular carcinoma: expansion of the tumor size limits does not adversely impact survival. Hepatology 33: 1394-1403.

47. Sharma P, Balan V, Hernandez JL, Harper AM, Edwards EB, et al. (2004) Liver transplantation for hepatocellular carcinoma: the MELD impact. Liver Transpl 10: $36-41$.

48. Abrams P, Marsh JW (2010) Current approach to hepatocellular carcinoma. Surg Clin North Am 90: 803-816.

49. Duffy JP, Vardanian A, Benjamin E, Watson M, Farmer DG, et al. (2007) Liver transplantation criteria for hepatocellular carcinoma should be expanded: a 22year experience with 467 patients at UCLA. Ann Surg 246: 502-509.

50. Mulier S, Ni Y, Jamart J, Ruers T, Marchal G, et al. (2005) Local recurrence after hepatic radiofrequency coagulation: multivariate meta-analysis and review of contributing factors. Ann Surg 242: 158-171.

51. Santambrogio R, Opocher E, Zuin M, Selmi C, Bertolini E, et al. (2009) Surgical resection versus laparoscopic radiofrequency ablation in patients with hepatocellular carcinoma and Child-Pugh class a liver cirrhosis. Ann Surg Oncol 16: 3289-3298.

52. Bharat A, Brown DB, Crippin JS, Gould JE, Lowell JA, et al. (2006) Pre-liver transplantation locoregional adjuvant therapy for hepatocellular carcinoma as a strategy to improve longterm survival. J Am Coll Surg 203: 411-420.

53. Jarnagin W, Chapman WC, Curley S, D'Angelica M, Rosen C, et al. (2010) Surgical treatment of hepatocellular carcinoma: expert consensus statement. HPB (Oxford) 12: 302-310.

54. Shi XJ, Jin X, Wang MQ, Wei LX, Ye HY, et al. (2011) Outcomes of locoregional therapy for down-staging of hepatocellular carcinoma prior to liver transplantation. Hepatobiliary Pancreat Dis Int 10: 143-150.

55. Whitney R, Tatum C, Hahl M, Ellis S, Scoggins CR, et al. (2011) Safety of hepatic resection in metastatic disease to the liver after yttrium-90 therapy. J Surg Res. 166: 236-240.
56. Scheele J, Stangl R, Altendorf-Hofmann A (1990) Hepatic metastases from colorectal carcinoma: impact of surgical resection on the natural history. $\mathrm{Br} \mathrm{J}$ Surg 77: 1241-1246

57. Chapman WC, Hoff PM, Strasberg SM (2006) Selection of patients fo resection of hepatic colorectal metastases: expert consensus statement by Charnsangavej et al. Ann Surg Oncol 13: 1269-1270.

58. Aloia TA, Vauthey JN, Loyer EM, Ribero D, Pawlik TM, et al. (2006) Solitary colorectal liver metastasis: resection determines outcome. Arch Surg 141: 460466 .

59. Smith MD, McCall JL (2009) Systematic review of tumour number and outcome after radical treatment of colorectal liver metastases. Br J Surg 96: 1101-1113.

60. Nordlinger B, Sorbye H, Glimelius B, Poston GJ, Schlag PM, et al. (2008) Perioperative chemotherapy with FOLFOX4 and surgery versus surgery alone for resectable liver metastases from colorectal cancer (EORTC Intergroup tria 40983): a randomised controlled trial. Lancet 371: 1007-1016.

61. Figueras J, Torras J, Valls C, Llado L, Ramos E, et al. (2007) Surgical resection of colorectal liver metastases in patients with expanded indications: a singlecenter experience with 501 patients. Dis Colon Rectum 50: 478-488.

62. Figueras J, Burdio F, Ramos E, Torras J, Llado L, et al. (2007) Effect of subcentimeter nonpositive resection margin on hepatic recurrence in patients undergoing hepatectomy for colorectal liver metastases. Evidences from 663 liver resections. Ann Oncol 18: 1190-1195.

63. Brown RE, Bower MR, Martin RC (2010) Hepatic resection for colorectal liver metastases. Surg Clin North Am 90: 839-852.

64. Fong Y, Fortner J, Sun RL, Brennan MF, Blumgart LH, et al. (1999) Clinical score for predicting recurrence after hepatic resection for metastatic colorectal cancer: analysis of 1001 consecutive cases. Ann Surg 230: 309-318.

65. Nathan H, de Jong MC, Pulitano C, Ribero D, Strub J, et al. (2010) Conditional survival after surgical resection of colorectal liver metastasis: an international multi-institutional analysis of 949 patients. J Am Coll Surg 210: 755-764.

66. Iwatsuki S, Dvorchik I, Madariaga JR, Marsh JW, Dodson F, et al. (1999) Hepatic resection for metastatic colorectal adenocarcinoma: a proposal of a prognostic scoring system. J Am Coll Surg 189: 291-299.

67. Jones OM, Rees M, John TG, Bygrave S, Plant G (2005) Biopsy of resectable colorectal liver metastases causes tumour dissemination and adversely affects survival after liver resection. Br J Surg 92: 1165-1168.

68. Aloia T, Sebagh M, Plasse M, Karam V, Lévi F, et al. (2006) Liver histology and surgical outcomes after preoperative chemotherapy with fluorouracil plus oxaliplatin in colorectal cancer liver metastases. J Clin Oncol 24: 4983-4990.

69. Vauthey JN, Pawlik TM, Ribero D, Wu TT, Zorzi D, et al. (2006) Chemotherapy regimen predicts steatohepatitis and an increase in 90-day mortality after surgery for hepatic colorectal metastases. J Clin Oncol 24: 2065-2072.

70. Kooby DA, Fong Y, Suriawinata A, Gonen M, Allen PJ, et al. (2003) Impact of steatosis on perioperative outcome following hepatic resection. J Gastrointest Surg 7: 1034-1044

71. Vetelainen R, van Vliet A, Gouma DJ, van Gulik TM (2007) Steatosis as a risk factor in liver surgery. Ann Surg 245: 20-30.

72. Karoui M, Penna C, Amin-Hashem M, Mitry E, Benoist S, et al., (2006) Influence of preoperative chemotherapy on the risk of major hepatectomy for colorectal liver metastases. Ann Surg 243: 1-7.

73. D'Angelica M, Kornprat P, Gonen M, Chung KY, Jarnagin WR, et al. (2007) Lack of evidence for increased operative morbidity after hepatectomy with perioperative use of bevacizumab: a matched case-control study. Ann Surg Oncol 14: 759-765.

74. Reddy SK, Morse MA, Hurwitz HI, Bendell JC, Gan TJ, et al. (2008) Addition of bevacizumab to irinotecan- and oxaliplatin-based preoperative chemotherapy regimens does not increase morbidity after resection of colorectal liver metastases. J Am Coll Surg 206: 96-106.

75. Luo Y, Wang L, Chen C, Chen D, Huang M, et al. (2010) Simultaneous liver and colorectal resections are safe for synchronous colorectal liver metastases. $J$ Gastrointest Surg 14: 1974-1980.

76. Reddy SK, Pawlik TM, Zorzi D, Gleisner AL, Ribero D, et al. (2007) Simultaneous resections of colorectal cancer and synchronous liver metastases: a multiinstitutional analysis. Ann Surg Oncol 14: 3481-1391. 
Citation: Lowe K, Jeyarajah DR (2011) Integration of Surgery and Radioembolization in Treatment of Hepatic Tumors. J Nucl Med Radiat Ther 2:105. doi:10.4172/2155-9619.1000105

77. Azoulay D, Castaing D, Smail A, Adam R, Cailliez V, et al. (2000) Resection of nonresectable liver metastases from colorectal cancer after percutaneous portal vein embolization. Ann Surg 231: 480-486.

78. Makuuchi, M., Thai BL, Takayasu K, Takayama T, Kosuge T, et al. (1990) Preoperative portal embolization to increase safety of major hepatectomy for hilar bile duct carcinoma: a preliminary report. Surgery 107: 521-257.

79. Wicherts DA, de Haas RJ, Andreani P, Sotirov D, Salloum C, et al. (2010) Impact of portal vein embolization on long-term survival of patients with primarily unresectable colorectal liver metastases. Br J Surg 97: 240-250.

80. Vauthey JN, Chaoui A, Do KA, Bilimoria MM, Fenstermacher MJ, et al. (2000) Standardized measurement of the future liver remnant prior to extended liver resection: methodology and clinical associations. Surgery 127: 512-519.

81. Chu QD, Hill HC, Douglass HO Jr, Driscoll D, Smith JL,et al. (2002) Predictive factors associated with long-term survival in patients with neuroendocrine tumors of the pancreas. Ann Surg Oncol 9: 855-862.

82. Que FG, Nagorney DM, Batts KP, Linz LJ, Kvols LK et al. (1995) Hepatic resection for metastatic neuroendocrine carcinomas. Am J Surg 169: 36-42.

83. Sarmiento JM, Heywood G, Rubin J, Ilstrup DM, Nagorney DM, et al. (2003) Surgical treatment of neuroendocrine metastases to the liver: a plea for resection to increase survival. J Am Coll Surg 197: 29-37.

84. Akerstrom G (1996) Management of carcinoid tumors of the stomach, duodenum, and pancreas. World J Surg 20: 173-182.

85. Kim SJ, Kim JW, Han SW, Oh DY, Lee SH, et al. (2010) Biological characteristics and treatment outcomes of metastatic or recurrent neuroendocrine tumors: tumor grade and metastatic site are important for treatment strategy. BMC Cancer 10: 448.

86. Sarmiento JM, Que FG (2003) Hepatic surgery for metastases from neuroendocrine tumors. Surg Oncol Clin N Am 12: 231-242.

87. Hellman P, Ladjevardi S, Skogseid B, Akerström G, Elvin A (2002) Radiofrequency tissue ablation using cooled tip for liver metastases of endocrine tumors. World J Surg 26: 1052-1056.
88. Henn AR, Levine EA, McNulty W, Zagoria RJ (2003) Percutaneous radiofrequency ablation of hepatic metastases for symptomatic relief of neuroendocrine syndromes. AJR Am J Roentgenol 181: 1005-1010.

89. de Baere T, Elias D, Dromain C, Din MG, Kuoch V, et al. (2000) Radiofrequency ablation of 100 hepatic metastases with a mean follow-up of more than 1 year. AJR Am J Roentgenol 175: 1619-1625.

90. Kettenbach J, Köstler W, Rücklinger E, Gustorff B, Hüpfl M, et al. (2003) Percutaneous saline-enhanced radiofrequency ablation of unresectable hepatic tumors: initial experience in 26 patients. AJR Am J Roentgenol 180 1537-1545.

91. Chung MH, Pisegna J, Spirt M, Giuliano AE, Ye W, et al. (2001) Hepatic cytoreduction followed by a novel long-acting somatostatin analog: a paradigm for intractable neuroendocrine tumors metastatic to the liver. Surgery 130: 954 962.

92. Vogl TJ, Naguib NN, Zangos S, Eichler K, Hedayati A, et al. (2009) Liver metastases of neuroendocrine carcinomas: interventional treatment via transarterial embolization, chemoembolization and thermal ablation. Eur $\mathrm{J}$ Radiol 72: 517-528.

93. Vogl TJ, Gruber T, Naguib NN, Hammerstingl R, Nour-Eldin NE, et al. (2009) Liver metastases of neuroendocrine tumors: treatment with hepatic transarterial chemotherapy using two therapeutic protocols. AJR Am J Roentgenol 193 941-947.

94. Sward C, Johanson V, Nieveen van Dijkum E, Jansson S, Nilsson O, et al (2009) Prolonged survival after hepatic artery embolization in patients with midgut carcinoid syndrome. Br J Surg 96: 517-521.

95. Strosberg JR, Choi J, Cantor AB, Kvols LK (2006) Selective hepatic artery embolization for treatment of patients with metastatic carcinoid and pancreatic endocrine tumors. Cancer Control 13: 72-78.

96. Lehnert T (1998) Liver transplantation for metastatic neuroendocrine carcinoma an analysis of 103 patients. Transplantation 66: 1307-1312. 